\title{
利用数字化网络资源 “拓宽习作空间,引导快乐作文”
}

\author{
王蕴卓 \\ 吉化第六小学校
}

DOI:10.32629/er.v3i6.2803

[摘 要] 充分利用数字化网络资源, 熟练运用现代信息教育技术,与小学习作教学紧密结合,在教学实践中努力去探索快乐作文的新途径, 即: “立足课内文本” “拓展课内文本” “借助课外读物” “链接学生生活” “能力综合培养”五大空间。其中“画写结合”的方式成为引导学生快 乐作文的特色。

[关键词] 数字化网络资源; 快乐作文; 现代信息教育技术

\section{引言}

在教学实践中, 我越来越感到数字化网络教育资源在小学语文教学中 具有不可或缺的地位和作用, 具有鲜明的时代性和强劲的生命力。我们致 力于建设开放而有活力的新型语文课堂, 就必须充分应用大容量的数字化 教育资源。只有合理运用好了这些资源, 才能为学生创造自主、合作、探 究的学习空间, 才能使课堂充满活力与效力。

作文教学是整个语文教学的重要组成部分, 是培养学生语文综合素质 的重要方式。在实际教学中, 如果能将网络教学资源与作文教学结合, 将会 事半功倍。所以, 在作文教学中我从小学起始年级就开展 “拓宽习作空间, 引导快乐作文”的实验研究。以吴立岗教授的作文教学思想为指导, 以“拓 宽习作空间, 引导快乐作文”为主要研究内容, 运用数字化信息资源, 以“激 发学生的作文兴趣, 培养良好的作文习惯” 为突破口, 在拓宽习作空间, 引 导快乐作文的教学方面进行了研究和实践。取得了一定成果。

\section{1 立足课内文本、增强直观性}

教材中有许多比喻句, 但是, 对于低年级的孩子来说, 理解并不容易, 我就利用网络多媒体, 制作课件, 增强直观性, 使学生便于理解。如: 学习 比喻句, 以此句为例。“晚上, 满天的星星, 像无数颗珍珠撒在碧玉盘里。” 一句, 学生不理解 “碧玉盘” 是什么样子的, 对于 “珍珠” 也是模模糊糊的, 所以不好理解作者的这个比喻。我通过网络收集到视频资料, 让学生直观 感受到两种事物的形象, 引导学生分析 “珍珠” “碧玉盘” 指什么? 想象还 可以把星星比做什么? 出示相关图片, 扩展学生思维, 激发学生的兴趣和 想象力, 找到两种事物的相似点进行比喻: 满天的星星像眼睛眨呀眨; 像 蝴蝶飞呀飞; 像顽皮的小精灵; 像一只只萤火虫; 像闪闪发光的钻石等。 还可以用XX像XX说一句话。对于他们或天真或幼稚的想象, 只要符合他们 的道理, 我都给予肯定, 并充分尊重他们的天性。

如: 有的 ……有的 ……还有的 …… 有 $\cdots$ 有 $\cdots$ 还有 $\cdots$ ) 这个句式最常用, 我通过相关视频和图片, 引导学生去观察、收集, 然后表达。如: 市场上: 蔬菜可真多呀...... ; 水果的种类可真多呀...... ; 商店里的商品真是琳琅满 目…… 书店里图书的种类可真不少...... ; 公园里的人真多...... ; 大扫除 时同学们干得可起劲了....... 放学后同学们各自参加自己喜欢的课外 班……; 秋天到了, 果园里的果子成熟了 …; 节日里天空真美丽, 礼花齐 放……这样练习的同时出示课件, 引发了他们的兴趣, 激发了想象力。培养 了他们观察、体验、表达的能力。

其实, 教师能做到立足文本, 通过网络教学, 为学生提供表达的内容, 拓展想象空间, 学生自然就会快乐表达了。

\section{2 拓展课内文本、创设故事情境}

利用网络资源, 拓展课内文本, 为学生的想象写话创设课文情境。

例如学习《小动物的家》。我通过播放视频, 从 “家”引入, 问孩子们:
家是什么? 没想到六、七岁的孩子对 “家” 有自己独特的理解。他们说: “家是有一个温暖的房子, 漂亮的房子。” “可以休息, 睡觉的地方。”一家 人在一起。” “有爸爸、妈妈陪伴你。” “是一个很舒服的地方。” 等等。孩 子们理解与表达显然是不够的。我又引导学生们说: 家是什么呢? 老师给 你们讲一个故事。引导边看视频边听老师讲解。这是1983年发生在卢旺达 的一个真实的故事。也许能给家做一个贴切的注释。卢旺达内战期间, 有 一个叫热拉尔的人, 37 岁, 他的家有 40 口人, 父母、兄弟、姐妹、妻儿几乎 全部离散丧生。最后, 绝望的热拉尔打听到 5 岁的小女儿还活着, 辗转数地, 冒着生命危险找到了自己的亲生骨肉后, 他悲喜交集, 将女儿紧紧搂在怀 里, 第一句话就是: “我又有家了。” 学生听了, 有的泪光盈盈, 有的默不作 声, 沉思不语, 数秒钟后, 有的孩子举手了。“老师家是一个有爱的地方。” “有爱才有家。” “家是一个我肚子饿了可以吃到香喷喷饭菜的地方。” “家 是一个你生病了, 有人照顾你的地方。” “家是一个我受了委屈可以哭诉的 地方。”.......

这节课结束了, 学生将课堂的发言内容写成了一篇作文《家是什么》。 这节课, 不禁使我想到我们的作文教学应该是什么样子的呢? 应该是让学 生感受到诗一样美好; 能得到精神的享受; 是一幅多姿多彩、形象鲜明的 画; 是一首情真意切, 感人肺腑的歌; 是学生精神世界的一道风景; 是个 性飞扬的; 是能带来生命温暖的; 是会喷射出缤纷的色彩的; 是充满生命 活力的、灵动的、飞扬的……如果只限于课内文本的教学, 那会给我们的 教学给学生的成长带来多大的遗憾呀!

“拓展课内文本, 想象写话, 提升思维”我觉得这一途径是行之有效的, 为学生的习作拓展了空间, 是快乐作文的源泉。落实研究目标, 的确需要我 们的教师的智慧、艺术、爱心和耐心, 更需要科学的方法。

\section{3 借助课外读物、拓宽表达空间}

在充分利用好课本以外, 还适时适量地从报刊、杂志、网络上选取优 美的文章, 有趣的故事等课外读物, 让学生阅读, 以激发学生写话的兴趣, 拓宽写话的视野与空间, 提高作文水平。

晨读时, 我边播放视频图像, 边深情的向全班同学朗诵了朱自清的散 文《春》。多少个春天过去了, 学生们依然记着《春》, 记着我深情诵《春》 的那一刻。他们用质朴无华的语言告诉我, 听了我诵的《春》, 他们觉得真 美! 不知什么时候, 我发现孩子们竟然有了《春》的打印稿, 他们也学着我 的样子背着《春》。他们都可以整齐地把整篇散文背出来了! 我惊喜! 也 更柁异! 我想: 这是我借助这篇文章, 拓展学生习作空间的极好机会, 所以 在我领着学生品读赏读《春》后, 让孩子们试着以这种细淢的笔触来写 《秋》。

我问学生: 秋天到了, 周围的景物有了哪些变化? 学生用自己积累、 喜欢的词语说出了天、大雁、树叶、果子、菊花、稻田、秋雨等景物特点。 
语言很美, 感情很真。后来, 我让他们用一句话赞美秋天。学生们说出: 秋 天真美啊! 秋天是一首美妙的歌! 秋天真是一个如诗如画、多彩多姿的季 节! 等等。

通过实践证明了教师精心地从课外读物中选择有益的补充, 激发起学 生兴趣, 同时搭建习作平台, 学生就会在教师的引领下走上快乐作文的道 路, 拓展了习作的空间, 作文教学也会到了一个 “润物无声” 的境界。

\section{4 链接学生生活、激发个性表达}

叶圣陶先生说过: “生活就如源泉, 文章犹如溪水。泉源丰盈而不枯竭, 溪水自然活泼地流个不歇。” 因此, 我引导学生关注生活、自主体验、个性 表达、快乐作文。

一年365天, 节日有很多, 每个节日, 都蕴涵着文化和民俗, 散发着感人 的鬼力, 也容易引起学生的心灵共鸣, 产生写的欲望。我及时引导学生从生 活中汲取写作素材, 对学生来说可谓情之所至, 水到渠成。在浓厚的兴趣中 享受写话带来的成功的快乐心情。如过年、中秋节、端午节我通过收集网 络上的相关视频, 制作动画课件, 引导学生感受节日的文化, 学生们才能写 出自己独特的感受。

再比如夏天到了, 引导学生观察各种水果, 通过实物、图片、视频等资 料, 让学生看一看, 摸一摸, 闻一闻, 尝一尝。掂一掂, 问一问。有了生活, 有了体验, 学生写起作文自然感到快乐有趣。

教师的责任就在于让学生回归生活, 创造机会, 将习作活动置于现实 的生活背景之中, 以疏通学生的习作源泉, 为学生的习作提供有利的条件 和创作的空间, 鼓励他们自由表达和有创意的表达。

\section{5 综合能力培养、形成表达特色}

由易到难, 循序渐进的练习, 将观察、思维、表达三种能力结合起来培 养。写观察日记、制作贺卡写祝福的话、写留言条、编童话故事、写生活 日记、画写结合。将三大能力通过多种形式综合培养。尤其是画写结合的 方式成为引导学生快乐作文的特色。

童话是孩子们最为喜爱的文学形式, 在整个作文教学过程中, 我经常 让学生们用画写结合的方法写童话。

一次我制作音频课件, 给学生们讲了一个没有结尾只有悬念的童话故 事。说有几只小松鼠在河边草地上玩球, 不小心将球踢入水中, 怎么办呢? 于是, 小松鼠们想办法, 最后把球去上来了。显然他们是怎么想办法的? 想 出了什么办法? 是故事的空白, 也是学生们想象的空间。我让学生们通过
画写结合的方法自己画出四幅图, 写四段话。即: 河边踢球、皮球落水、 想办法捞球、球捞上来了。并且重点想一想小松鼠们的神态、动作、语言、 心理活动等等。结果, 孩子们的表现出人意料的好, 他们的思维空间相当广 阔, 想象力极为丰富。

把学生画的内容展示在大屏幕上, 孩子们异常兴奋。有的说：请小鸭 子帮忙, 因为它会游泳。还有的说: 请大象伯伯, 大鼻子一卷, 轻轻松松完 成。有的说: 小松鼠齐心协力用一张网把球网住。还有的说: 小松鼠坐在 一只大木盆里, 划到水中捞球。有的说: 小松鼠坐在乌龟背上把球捞上来。 更有创意的想法是：用 “猴子捞月亮” 的办法, 大伙一个连一个, 像一条链 子一直连到水里把球捞上来。而且, 学生们画面生动、传神, 作文内容具体、 细致, 从始至终兴趣盎然。

学生的观察、想象、思维、表达能力及道德感、责任感等得到了提升。 学生作文言之有物, 言之有序, 情真意切, 语言充满童贞童趣, 作文能力明 显提高。

充分利用学校数字化资源, 熟练运用现代信息教育技术, 广泛深入地 了解传统及现代的作文教学理论与思想, 并在教学研究中努力去实践这些 理念, 博采众长, 独辟蹊径。形成了 “一个教学模式”、“五大教学空间”、 “一大教学特色”。即: 激发兴趣一一关注生活一一自主体验一一快乐表 达的教学模式。“立足课内文本” “拓展课内文本” “借助课外读物” “链接 学生生活” “能力综合培养” 五大空间; 尤其是 “画写结合” 的方式成为 引导学生快乐作文的一大特色。

\section{6 结语}

学校的数字化教育资源的开发和利用充分发挥了教师自身的主动性 和创造性, 同时也极大地促进了教师的专业化发展, 给教学带来巨大的变 化, 使学生在习作方面获得了多方面的发展和提高。

\section{[参考文献]}

[1]郭伟业.数字化校园网建设对网络资源如何再分配的制约因素探 讨[J].现代营销(经营版),2018(11):85-86.

[2]薛玮. 小学快乐作文教学实践初探 [J]. 教育教学论 坛,2014(50):242-243.

[3]郑华.在快乐中生成作文, 在作文中品味快乐 [J].中国教 师,2016(S1):45. 